\section{Petrographic and paragenetic study of uranium mineralization along the Midwest Trend, Northeastern Athabasca Basin}

Daniel Ferguson 1,*, Guoxiang $\mathrm{Chi}^{1}$, Charles Normand $^{2}$, Patrick Ledru ${ }^{3}$, Odile MaufraisSmith $^{3}$

The Athabasca Basin in northern Saskatchewan is host to many world-class uranium deposits associated with the unconformity between the Paleoproterozoic sandstone of the basin and the underlying crystalline basement (Jefferson et al., 2007). While the style and tonnage of these deposits vary, the current genetic model for unconformity-related uranium deposits has been a practical tool for exploration in the Athabasca Basin. However, the factors which control the location and formation of these deposits is still not fully understood. A paragenetic and petrographic study of mineralization along the Midwest Trend, located on the northeastern margin of the Athabasca Basin, aims to refine the current model and to address the general problem: What are the factors which control mineralization and nonmineralization? The Midwest Trend will be used as a "modèle réduit" for uranium mineralization, as it displays many features characteristic of unconformity type deposits. The Midwest Trend comprises three mineral leases that encompass two uranium deposits, the Midwest Main and Midwest A (Allen et al., 2017a, b). Mineralization occurs along a NE-trending graphitic structure, and is hosted by the sandstone, at the unconformity, and in much lesser amounts in the underlying basement rocks. Petrographic observations aided by the use of RAMAN spectroscopy and SEM-EDS, have been used to create a paragenetic sequence of mineralization (Fig.1). Future work will focus on fluid inclusion studies using microthermometry, LA-ICP-MS, and mass spectrometry of contained gases.

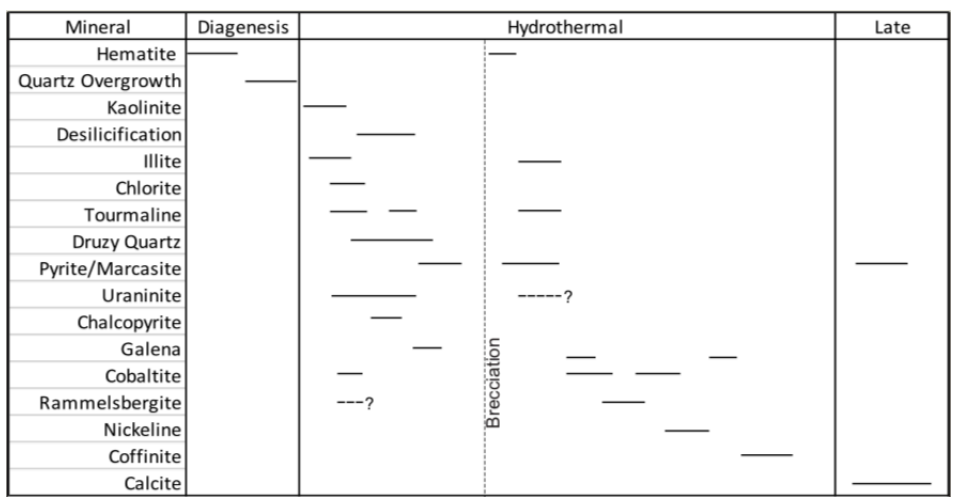

Figure 1: Preliminary paragenetic sequence for mineralization and alteration at the Midwest Main deposit, which is located at the unconformity. It does not include the paragenetic sequence of the basement

\section{References:}

Allen, T., Quirt, D., Masset, O. (2017a). Midwest A Uranium Deposit, Midwest Property, Northern Mining District, Saskatchewan, NTS Map Area 741/8: 2017 Mineral Resource Technical Report. AREVA Resources Canada Inc. Internal Report No. 17-CND33-01.

Allen, T., Quirt, D., Masset, O. (2017b). Midwest Main Uranium Deposit, Midwest Property, Northern Mining District, Saskatchewan, NTS Map Area 741/8: 2017 Mineral Resource Technical Report. AREVA Resources Canada Inc. Internal Report No. 17-CND-33-01.

Jefferson, C.W., Thomas, D.J., Gandhi, S.S., Ramaekers, P., Delaney, G., Brisbin, D., Cutts, C., Portella, P., and Olson, R.A., 2007: Unconformity-associated uranium deposits of the Athabasca Basin, Saskatchewan and Alberta. Geological Survey of Canada, Bulletin 588, p. 23-67.

\footnotetext{
1 Department of Geology, University of Regina, Regina SK, Canada

2 Saskatchewan Geological Survey, Ministry of Energy and Resources, Regina SK, Canada

3 Orano Canada Ltd., Saskatoon SK, Canada

* Correspondence: dpf949@uregina.ca
} 
